\title{
THE EVALUATION OF THYROID FUNCTION, ANTITHYROGLOBULINE ANTIBODY AND THYROID PEROXIDASE ANTIBODY IN CASE OF SPONTANEOUS ABORTION
}

\author{
By \\ Ahmed Hafez Ahmed Eid, Abdulrhman Mostafa Anber, Taher \\ Mohamed Mostafa and Medhat Ali Salah Abd El-Ghafar* \\ Departments of Obstetrics and Gynecology and *Clinical Pathology, Faculty of Medicine \\ Al-Azhar University \\ Corresponding author: Ahmed Hafez Ahmed Eid,
}

Mobile: (+20) 01000837523, E-mail: eldashahmed08@gmail.com

\begin{abstract}
Background: Abortion is the interruption and/or termination of pregnancy, either spontaneously or intentionally, before the fetus develops sufficiently to survive. About $80 \%$ of abortions occur in the first 12 weeks of pregnancy. The underlying mechanism in about half of cases involves chromosomal abnormalities.

Objective: To evaluate the association between TSH, T3, T4, anti-thyroglobulin antibody and thyroid peroxidase antibody in women with spontaneous abortion.

Patients and methods: This study was conducted on 60 female patients in the age group of 21-35 years recruited from the outpatient and inpatient clinics of the Department of Obstetrics and Gynecology, Tanta University Hospital, this study period February 2019 to July 2020. Approval of the medical ethics committee and signing written informed consent. The levels of TSH, T3, T4, antithyroglobin antibody and thyroid peroxidase antibody were determined.
\end{abstract}

Results: There was no statistically significant relation between spontaneous abortion and TSH, T3, T4, antithyroglobulin antibody and thyroid peroxidase antibody.

Conclusion: No need to screen for subclinical hypothyroidism and thyroid autoimmunity in all pregnancy.

Keywords: Abortion, Thyroid function, Antithyroglobuline antibody, thyroid peroxidase antibody.

\section{INTRODUCTION}

Abortions may occur for many reasons, not all of which can be identified. Some of these causes include genetic, uterine, or hormonal abnormalities, reproductive tract infections, and tissue rejection. Most clinically apparent abortions (two-thirds to three-quarters in various studies) occur during the first trimester (Francis, 2011). About $30 \%$ to $40 \%$ of all fertilized eggs abort, often before the woman knows she is pregnant (Health and Services, 2012).

Clinical investigation of pregnancy loss is sometimes initiated after two consecutive spontaneous abortions, especially when fetal heart activity has been identified before pregnancy losses, when the women are older than 35 years of age, or when the couple has had difficulty conceiving (Fox-Lee and 
Schust, 2013). It affects approximately $1 \%-3 \%$ of couples who are trying to conceive (Carrington et al., 2011).

Several conditions are known to contribute to recurrent abortion, including parental chromosome abnormalities, structural uterine anomalies, and antiphospholipid syndrome ( $L i$ et al., 2012). However, the role played by autoimmune disorders in recurrent abortion is rather controversial. Thyroid dysfunction and thyroid autoimmunity are both associated with recurrent abortion (Abalovich et al., 2010).

Stagnaro-Green et al. (2011) found that the presence of thyroid peroxidase (TPO) or thyroglobulin antibodies in the first trimester of pregnancy is a risk factor for subsequent spontaneous pregnancy loss. These results were confirmed by other investigators. Pratt et al. (2011) studied the significance of the presence of thyroid antibodies before pregnancy in women with a history of habitual abortion and found these antibodies to increase the risk for yet another abortion significantly. Impaired maternal thyroid hormone availability may induce irreversible brain damage with consequent neurological abnormalities (Walker et al., 2010).

Allan et al. (2011) showed that TSH levels above $6 \mathrm{mU} / \mathrm{l}$ are significantly associated with a higher frequency of stillbirth. Both low and high TSH and Free $\mathrm{T} 4$ to be associated with abortion, fetal or neonatal death (child loss).

Autoimmune thyroid disorders are characterized by the presence of antithyroid antibodies, specifically antithyroglobulin and antithyroid peroxidase. Thyroglobulin is a molecule produced by the thyroid cells and stored in thyroid colloid. The primary function of thyroglobulin is the storage and synthesis of thyroid hormones. Thyroid hormones (T3 and T4) are synthesized on thyroglobulin. Elevations in the serum concentration of this autoantibody may be identified in any condition that results in an abnormal or damaged thyroid follicular structure. Thyroid peroxidase is an enzyme responsible for iodination of tyrosine residues along with coupling of iodinated residues to form thyroid hormones. The role of TSH, the primary trophic hormone of the thyroid, is thyroid growth and development; therefore, thyroid cell activation stimulates thyroid hormone synthesis (Li et al., 2019).

Women with antithyroid antibodies (ATA), face double risk of abortion as against women without them. Increased thyroglobulin and thyroid peroxidase auto-antibodies level show relationship to an increased abortion rate. About 31 percent of women experiencing recurrent spontaneous abortion (RSA) are positive to one or both antibodies (Fröhlich and Wahl, 2017).

The aim of this study was to evaluate the association between TSH, T3, T4, antithyroglobulin antibodies and Thyroid peroxidase antibody in women with spontaneous abortion.

\section{PATIENTS AND METHODS}

This study was conducted on 60 female patients in the age group of 21-35 years recruited from the outpatient and inpatient clinics of the Department of Obstetrics and Gynecology, Tanta University Hospital, this study period February 2019 to July 2020. Approval of the medical 
ethics committee and signing a written informed consent.

\section{Patients were divided in two equal groups:}

- Group A: Pregnant women with normal pregnancy without history of abortion more than 12 weeks and below 20 weeks.

- Group B: Pregnant women aborting whatever any type of abortion more than 12 weeks and below 20 weeks.

\section{Inclusion criteria:}

Pregnant women with age between 21 to 35 years old, primigravidas or multigravidas, Gestational age above 12 weeks and below 20 weeks of gestation calculated according to last menstrual period (lmp) with an early ultrasound confirmation and euthyroid.

\section{Exclusion criteria:}

History of consanguinity, history of thyroid disease, history of major fetal abnormalities, history of pregnancy losses or fetal death above 20 weeks of gestation, women with chronic medical disorders, women with autoimmune disorders, women already on treatment for thyroid dysfunction and women with history of cervical incompetence, bicornate uterus, uterine septum or any other uterine pathology.

All patients enrolled in the study were submitted to complete history taking, complete general examination, local examination of thyroid gland and ultrasonographic scanning. Laboratory investigations included: TSH, T3, T4 level, anti-thyroglobulin antibodies and thyroid peroxidase antibody.

\section{Statistical analysis:}

Analysis of data was done using Statistical Package for the Social Sciences version 22 (SPSS Inc., Chicago, IL, USA). Quantitative variables were described in the form of mean and standard deviation. Qualitative variables were described as number and percent. In order to compare parametric quantitative variables between two groups, MannWhitney $U$ test was performed. Qualitative variables were compared using chi-square (X2) test or Fisher's exact test when frequencies were below five. $P$ value $<0.05$ was considered significant.

\section{RESULTS}

In control group, the level of TSH was normal in $90 \%$ patients and abnormal in $0.33 \%$ patients with a mean value $3.85 \pm$ $0.96(\mu \mathrm{IU} / \mathrm{ml})$. In cases group, the level of TSH was normal in $86.7 \%$ patients and abnormal in $10 \%$ patients with a mean value of $4.5 \pm 1.75(\mu \mathrm{IU} / \mathrm{ml})$. There was no statistically significant difference between the two groups regarding TSH level $(\mathrm{p}=0.299)$ (Table 1). 
Table (1): Comparison between the two studied groups according to TSH

\begin{tabular}{|c|c|c|c|c|c|}
\hline \multirow{2}{*}{ GSH Groups } & \multicolumn{2}{|c|}{$\begin{array}{c}\text { Control } \\
(\mathbf{n = 3 0})\end{array}$} & \multicolumn{2}{c|}{$\begin{array}{c}\text { Cases } \\
(\mathbf{n = 3 0})\end{array}$} & \multirow{2}{*}{ P-value } \\
\cline { 2 - 5 } & $\mathbf{N o .}$ & $\mathbf{\%}$ & No. & $\%$ & \\
\hline $\begin{array}{c}\text { Normal } \\
(\mathbf{0 . 3 5 - 4 . 8} \boldsymbol{\mu I U} / \mathbf{m l})\end{array}$ & 27 & 90 & 25 & 83.3 & \multirow{2}{*}{0.299} \\
\hline Abnormal & 1 & 3.3 & 3 & 10 & \\
\hline Min. - Max. & \multicolumn{2}{|c|}{$0.58-5$} & \multicolumn{2}{|c|}{$0.49-9.0$} & \multirow{2}{*}{0.081} \\
\hline Mean \pm SD. & \multicolumn{2}{|c|}{$3.85 \pm 0.96$} & \multicolumn{2}{|c|}{$4.5 \pm 1.75$} & \\
\hline Median & \multicolumn{2}{|c|}{3} & \multicolumn{2}{|c|}{4} & \\
\hline
\end{tabular}

In control group, the level of $\mathrm{T} 3$ was normal in $90 \%$ patients and abnormal in $3.3 \%$ patients with a mean value $130.17 \pm$ $63.58(\mathrm{ng} / \mathrm{dl})$. In cases group, the level of T3 was normal in $86.7 \%$ patients and abnormal in $6.7 \%$ patients with a mean value of $159.43 \pm 61.08(\mathrm{ng} / \mathrm{dl})$. There was no statistically significant difference between the two groups regarding T3 level $(\mathrm{p}=0.553)$ (Table 2).

Table (2): Comparison between the two studied groups according to T3

\begin{tabular}{|c|c|c|c|c|c|}
\hline \multirow{2}{*}{ T3 Groups } & \multicolumn{2}{|c|}{$\begin{array}{c}\text { Control } \\
(\mathbf{n = 3 0})\end{array}$} & \multicolumn{2}{|c|}{$\begin{array}{c}\text { Cases } \\
(\mathbf{n = 3 0})\end{array}$} & \multirow{2}{*}{ P-value } \\
\cline { 2 - 5 } & No. & \% & No. & \% & \\
\hline $\begin{array}{c}\text { Normal } \\
(\mathbf{9 0 - 1 9 0 n g / d l )}\end{array}$ & 27 & 90 & 26 & 86.7 & \multirow{2}{*}{0.553} \\
\hline Abnormal & 1 & 3.3 & 2 & 6.7 & \\
\hline Min. - Max. & \multicolumn{2}{|c|}{$88-197$} & \multicolumn{2}{|c|}{$81-189$} & \multirow{2}{*}{0.074} \\
\hline Mean \pm SD. & \multicolumn{2}{|c|}{$130.17 \pm 63.58$} & \multicolumn{2}{|c|}{$159.43 \pm 61.08$} & \\
\hline Median & \multicolumn{2}{|c|}{145} & \multicolumn{2}{|c|}{156} & \\
\hline
\end{tabular}

In control group, the level of T4 was normal in $90 \%$ patients and abnormal in $3.3 \%$ patients with a mean value $9.39 \pm$ $3.72(\mathrm{ng} / \mathrm{dl})$. In cases group, the level of $\mathrm{T} 4$ was normal in $86.7 \%$ patients and abnormal in $6.7 \%$ patients with a mean value of $10.71 \pm 3.85(\mathrm{ng} / \mathrm{dl})$. There was no statistically significant difference between the two groups regarding $\mathrm{T} 4$ level $(\mathrm{p}=0.553)$ (Table 3).

Table (3): Comparison between the two studied groups according to T4 .

\begin{tabular}{|c|c|c|c|c|c|}
\hline \multirow{2}{*}{$\mathrm{T4} \longrightarrow$ Groups } & \multicolumn{2}{|c|}{$\begin{array}{l}\text { Control } \\
(\mathbf{n}=\mathbf{3 0})\end{array}$} & \multicolumn{2}{|c|}{$\begin{array}{c}\text { Cases } \\
(\mathbf{n}=\mathbf{3 0})\end{array}$} & \multirow[t]{2}{*}{ P-value } \\
\hline & No. & $\%$ & No. & $\%$ & \\
\hline $\begin{array}{c}\text { Normal } \\
(4-12 n g / d l)\end{array}$ & 27 & 90 & 26 & 86.7 & \multirow{2}{*}{0.553} \\
\hline Abnormal & 1 & 3.3 & 2 & 6.7 & \\
\hline Min. - Max. & \multicolumn{2}{|c|}{$2.3-11.6$} & \multicolumn{2}{|c|}{$3.2-11.6$} & \multirow{3}{*}{0.182} \\
\hline Mean \pm SD & \multicolumn{2}{|c|}{$7.39 \pm 3.72$} & \multicolumn{2}{|c|}{$8.71 \pm 3.85$} & \\
\hline Median & \multicolumn{2}{|c|}{10.3} & \multicolumn{2}{|c|}{10.55} & \\
\hline
\end{tabular}


In control group, the level of antithyroglobulin auto antibodies was normal in $86.7 \%$ patients and abnormal in $6.7 \%$ patients with a mean value of 32.62 $\pm 61.03(\mathrm{IU} / \mathrm{ml})$. In cases group the level of antithyroglobulin auto antibodies was normal in $73.3 \%$ patients and abnormal in
$20 \%$ patients with a mean value of 77.67 \pm 130.87 (IU/ml). There was no statistically significant difference between the two groups regarding antithyroglobulin auto antibodies level $(\mathrm{p}=0.127)$ (Table 4).

Table (4): Comparison between the two studied groups according to antithyroglobulin

\begin{tabular}{|c|c|c|c|c|c|}
\hline \multirow{2}{*}{ Groups } & \multicolumn{2}{|c|}{$\begin{array}{c}\text { Control } \\
(\mathbf{n = 3 0})\end{array}$} & \multicolumn{2}{c|}{$\begin{array}{c}\text { Cases } \\
(\mathbf{n = 3 0})\end{array}$} & \multirow{2}{*}{ P-value } \\
\cline { 2 - 5 } Antithyroglobulin & No. & $\%$ & No. & $\%$ & \\
\hline $\begin{array}{c}\text { Normal } \\
\text { (up to 115 IU/ml) }\end{array}$ & 26 & 86.7 & 22 & 73.3 & \multirow{2}{*}{0.127} \\
\hline Abnormal & 2 & 6.7 & 6 & 20 & \\
\hline Min. - Max. & \multicolumn{2}{|c|}{$10.9-301$} & \multicolumn{2}{|c|}{$10.3-406$} & \multirow{2}{*}{0.105} \\
\hline Mean \pm SD. & \multicolumn{2}{|c|}{$32.62 \pm 61.03$} & $77.67 \pm 130.87$ & \\
\hline Median & \multicolumn{2}{|c|}{14.3} & \multicolumn{2}{|c|}{12.85} & \\
\hline
\end{tabular}

In control group, the level of thyroid peroxidase auto antibodies was normal in $86.7 \%$ patients and abnormal in $6.7 \%$ patients with a mean value of $24.36 \pm$ $52.21(\mathrm{IU} / \mathrm{ml})$. In cases group the level of thyroid peroxidase auto antibodies was normal in $73.3 \%$ patients and abnormal in $20 \%$ patients with a mean value of 28.65 \pm 53.19 (IU/ml). There was no statistically significant difference between the two groups regarding thyroid peroxidase autoantibodies level ( $\mathrm{p}=0.127)$ (Table 5).

Table (5): Comparison between the two studied groups according to thyroid peroxidase

\begin{tabular}{|c|c|c|c|c|c|}
\hline \multirow{2}{*}{ Thyroperoxidase } & \multicolumn{2}{|c|}{$\begin{array}{l}\text { Control } \\
(\mathbf{n}=\mathbf{3 0})\end{array}$} & \multicolumn{2}{|c|}{$\begin{array}{c}\text { Cases } \\
(\mathbf{n}=\mathbf{3 0}) \\
\end{array}$} & \multirow[t]{2}{*}{ P-value } \\
\hline & No. & $\%$ & No. & $\%$ & \\
\hline $\begin{array}{c}\text { Normal } \\
\text { (up to } 35 \text { IU/ml) }\end{array}$ & 26 & 86.7 & 22 & 73.3 & \multirow[t]{2}{*}{0.127} \\
\hline Abnormal & 2 & 6.7 & 6 & 20 & \\
\hline Min. - Max. & \multicolumn{2}{|c|}{$2.5-298$} & \multicolumn{2}{|c|}{$2.1-298$} & \multirow{3}{*}{0.760} \\
\hline Mean \pm SD. & \multicolumn{2}{|c|}{$24.36 \pm 52.21$} & \multicolumn{2}{|c|}{$28.65 \pm 53.19$} & \\
\hline Median & \multicolumn{2}{|c|}{13.1} & \multicolumn{2}{|c|}{12.35} & \\
\hline
\end{tabular}

\section{DISCUSSION}

We found that $10 \%$ of cases had abnormal TSH level. On the other hand, $3.3 \%$ of control group had abnormal TSH level. There was no significant difference in the TSH level in the two groups. $6.7 \%$ of cases had abnormal T3 level. On the other hand, $3.3 \%$ of control group had abnormal T3 level. There was no significant difference in the T3 level in the two groups. $6.7 \%$ of cases had abnormal T4 level. On the other hand and $3.3 \%$ of control group had abnormal T4 level. There was no significant difference between the two groups. 
We found that $20 \%$ of cases were positive for antithyroglobulin antibodies and $6.7 \%$ of control group were positive. No significant difference between the two groups. $20 \%$ of cases were positive for thyroid peroxidase antibodies. $6.7 \%$ of control groups no significant difference two groups.

In agreement with this study, Pratt et al. (2011) determined that $31 \%$ of the cases were positive compared to $19 \%$ of controls. The correlation was statistically non-significant.

Esplin et al. (2011) stated that $29.3 \%$ of the cases and $37 \%$ of control had positive result for both with no statistically significant difference.

Muller et al. (2010) a prospective study observed that pregnancy occurred in $48 \%$ of the antibody-positive women and in $28 \%$ of the antibody-negative women. Among those who became pregnant, miscarriage occurred in $33 \%$ of TPO antibody-positive women and in $19 \%$ of TPO antibody-negative women. The TSH level was abnormal $(<0.2 \mathrm{microIU} / \mathrm{mL})$ in only one of the TPO antibody-positive women who miscarried. There was no statistically significant difference.

In disagreement with this study, Bussan et al. (2010) in a case control study done on 28 euthyroid non-pregnant habitual aborters were analyzed for thyroglobulin (TG), thyroid peroxidase antibodies (TPO) and multigravida without previous abortions or endocrine dysfunctions served as controls. 39\% with recurrent spontaneous miscarriage, but only $7 \%$ controls demonstrated positive titers of TG, TPO, or both antibodies.
In contrary to this study, Dendrinos et al. (2011) in a case control study done on women with history of recurrent abortion and fertile women were tested with a chemiluminescence immunoassay. Results were compared using the chi-squared test. There was a higher frequency of antithyroglobulin auto antibodies in women with recurrent abortion compared to controls (37\% versus $13 \%$ ).

The current study found that adverse pregnancy outcomes levels are higher in patients with thyroid dysfunction, than normal control group, but this difference was not statistically significant.

\section{CONCLUSION}

There was no significant relation between spontaneous abortion and $\mathrm{TSH}$, T3, T4, anti-thyroglobulin antibody and thyroid peroxidase antibody. Therefore, no need to screen for subclinical hypothyroidism and thyroid autoimmunity in all pregnancy.

\section{REFERENCES}

1. Abalovich M, Alcaraz G, KleimanRubinsztein J, Pavlove MM, Cornelio $\mathrm{C}$ and Levalle O. (2010): The relationship of preconception thyrotropin levels to requirements for increasing the levothyroxine dose during pregnancy in women with primary hypothyroidism. Thyroid: Official Journal of the American Thyroid Association, 20(10):1175-8.

2. Allan W, Haddow J, Palomaki G, Williams J, Mitchell $M$ and Hermos R. (2011): Maternal thyroid deficiency and pregnancy complications: implications for population screening. Journal of Medical Screening, 7(3):127-30.

3. Bussen SS and Steck T. (2010): Thyroid antibodies and their relation to antithrombin antibodies, anticardiolipin antibodies and lupus anticoagulant in women with recurrent spontaneous abortions (antithyroid, 
anticardiolipin and antithrombin autoantibodies and lupus anticoagulant in habitual aborters). European Journal of Obstetrics \& Gynecology and Reproductive Biology, 74(2):139-43.

4. Carrington B, Sacks G and Regan L. (2011): Recurrent miscarriage: pathophysiology and outcome. Current Opinion in Obstetrics and Gynecology, 17(6):591-7.

5. Dendrinos S, Papasteriades C, Tarassi K, Christodoulakos G, Prasinos G and Creatsas G. (2011): Thyroid autoimmunity in patients with recurrent spontaneous miscarriages. Gynecological Endocrinology, 14(4):270-4.

6. Esplin MS, Branch DW, Silver $R$ and Stagnaro-Green A. (2011): Thyroid autoantibodies are not associated with recurrent pregnancy loss. American Journal of Obstetrics and Gynecology, 179(6):1583-6.

7. Fox-Lee L and Schust D. (2013): Recurrent pregnancy loss. Berek JS Berek and Novak's Gynecology, Pbl. Philadelphia: Lippincott Williams \& Wilkins. Pp. 1277-82.

8. Francis O. (2011): An analysis of 1150 cases of abortions from the Government RSRM Lying-in Hospital Madras. Journal of Obstetrics and Gynaecology of India, 10(1):6270 .

9. Fröhlich E and Wahl R. (2017): Thyroid Autoimmunity: Role of Anti-thyroid Antibodies in Thyroid and Extra-Thyroidal Diseases. Front Immunol., 8: 521-525.

10. Health UD and Services H. (2012): The health consequences of involuntary exposure to tobacco smoke: a report of the Surgeon General. Atlanta, GA: US Department of Health and Human Services, Centers for Disease Control and Prevention, Coordinating Center for Health Promotion, National Center for Chronic Disease Prevention and Health
Promotion, Office on Smoking and Health. Pp. 709.

11. Li J, Liu A, Liu H, Li C, Wang W, Han C, Wang $X$, Zhang $Y$, Teng $W$ and Shan $Z$. (2019): Maternal TSH levels at first trimester and subsequent spontaneous miscarriage: a nested case-control study. Endocrine Connections, 8(9):1288-1293.

12. Li T, Makris M, Tomsu M, Tuckerman E and Laird S. (2012): Recurrent miscarriage: aetiology, management and prognosis. Human Reproduction Update, 8(5):463-81.

13. Muller A, Verhoeff A, Mantel $M$ and Berghout A. (2010): Thyroid autoimmunity and abortion: a prospective study in women undergoing in vitro fertilization. Fertility and Sterility, 71(1):30-4.

14. Pratt DE, Kaberlein G, Dudkiewicz A, Karande $V$ and Gleicher N. (2011): The association of antithyroid antibodies in euthyroid nonpregnant women with recurrent first trimester abortions in the next pregnancy. Fertility and Sterility, 60(6):1001-5.

15. Stagnaro-Green A, Abalovich M, Alexander E, Azizi F, Mestman J, Negro R, Nixon A and Pearce EN (2011): Guidelines of the American Thyroid Association for the Diagnosis and Management of Thyroid Disease During Pregnancy and Postpartum. Pregnancy and Fetal Development, 21(10): 1081-92.

16. Walker JA, Illions EH, Huddleston JF and Smallridge RC. (2010): Racial comparisons of thyroid function and autoimmunity during pregnancy and the postpartum period. Obstetrics \& Gynecology, 106(6):1365-71. 


\section{AHMED HAFEZ AHMED EID et al.,}

تقييم وظائف الغدة الدرقية و الأجسام المضادة للثيروجلوبيولين

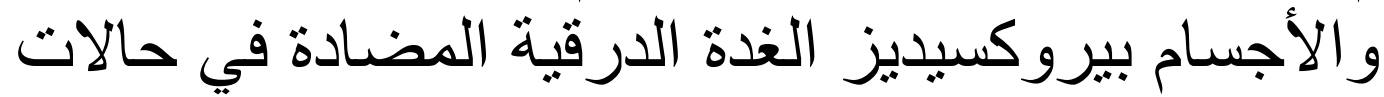
الاجهاض التلقائي

أحمد حافظ أحمد عيد, عبدالرحمن مصطفى عنبر, طاهر محمد مصطفي, مدحت على الى

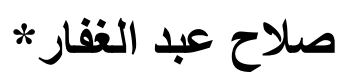

قسمي التوليد وامراض النساء، الباثولوجيا الاكلينيكة*، كلية الطب, جامعة الأزهر

E-mail: eldashahmed08@gmail.com

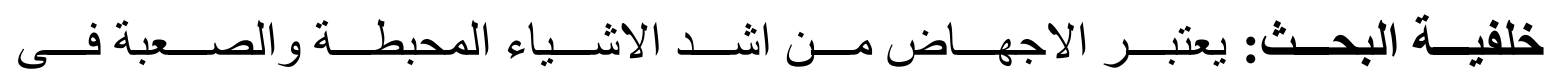

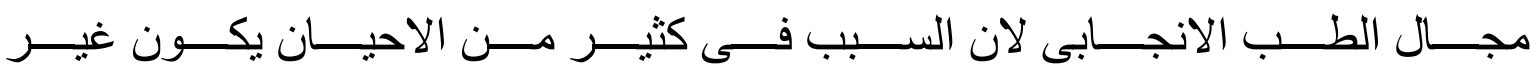

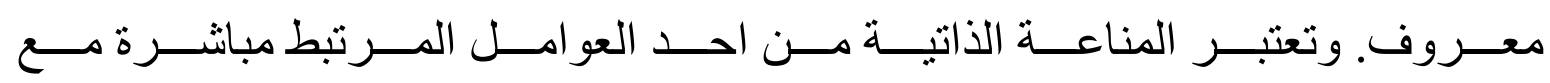
اسباب العقم وحدوث الاجهاض المتكرر بصورة خاصة.

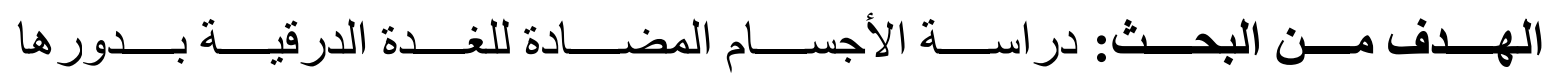

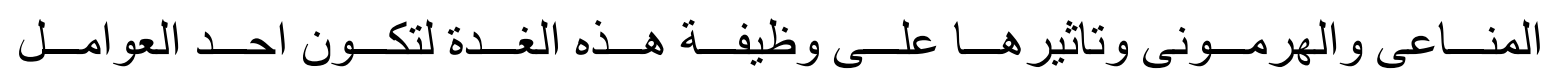
المؤثرة فى حدوث الاجهاض التلقائي.

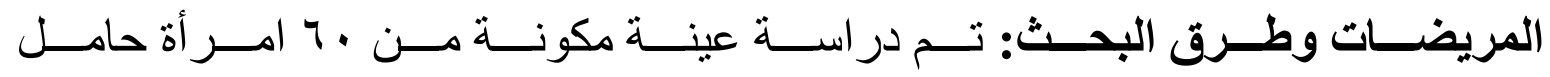

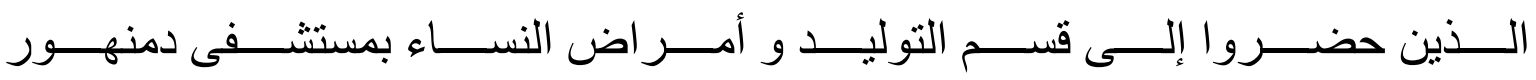

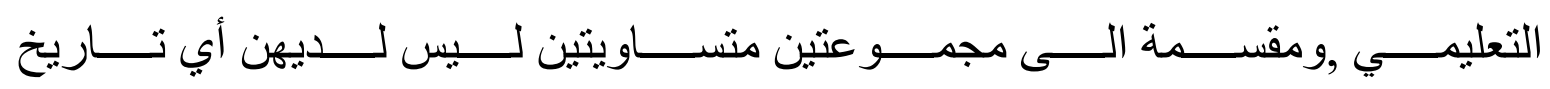

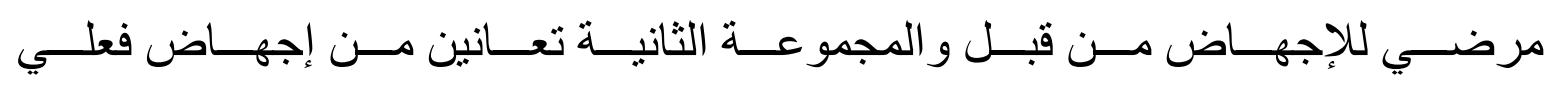

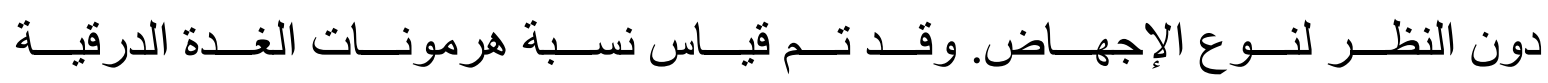

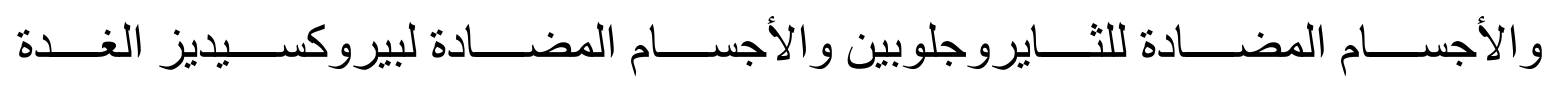

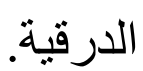




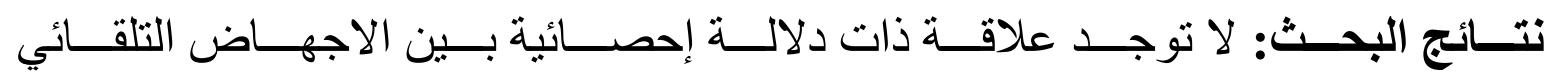

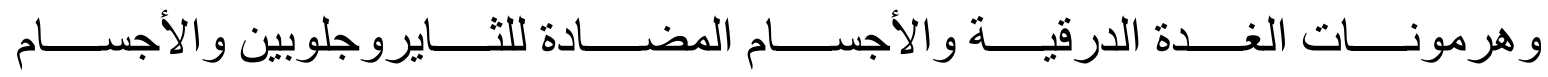
المضنادة لبيروكسيديز الغدة الدرقية.

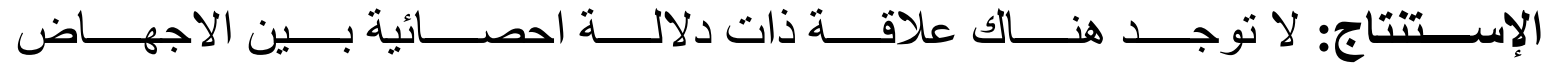

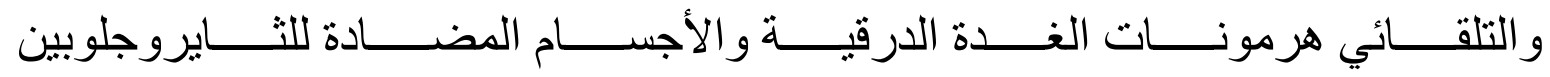
و الأجسام المضـادة لبيروكسيديز الغدة الدرقية لدى السبدات الحوامل.

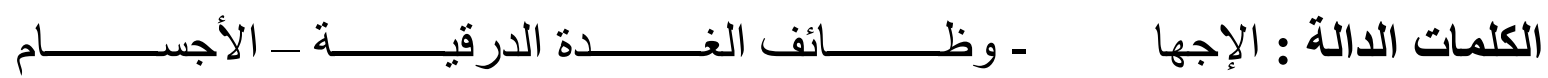

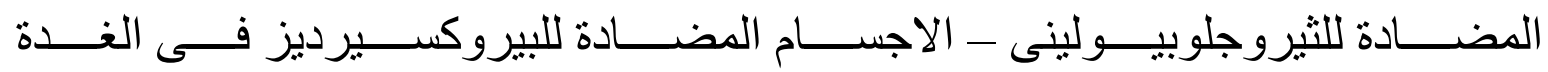
الدرقبة . 